\title{
Glomerular Selective Permeability to Macromolecular Neutral Dextrans in Experimental Diabetes
}

\author{
J. P. Pennell, N. Yanagawa, K. H. Hwang, M. M. Millard, and J. J. Bourgoignie \\ Division of Nephrology and Laboratory of the Howard Hughes Medical Institute, Department of Medicine, \\ University of Miami School of Medicine, Miami, Florida, USA
}

Summary. Rats with streptozotocin-induced chronic diabetes mellitus develop a glomerulopathy functionally manifested by proteinuria. The ability of the glomerular capillary wall to retard filtration of macromolecules was examined in 5 chronically diabetic Munich-Wistar rats exhibiting excessive proteinuria $(39 \pm 7 \mathrm{mg} / 24 \mathrm{~h}$, mean $\pm \mathrm{SEM})$ and 5 age-matched normal Munich-Wistar rats without increased proteinuria $(4.7 \pm 0.2 \mathrm{mg} / 24 \mathrm{~h})$. Urinary albumin excretion was not increased in the diabetic rats $(2.0 \pm 0.6 \mathrm{mg} / 24 \mathrm{~h}$ vs $1.6 \pm 0.3 \mathrm{mg} / 24 \mathrm{~h})$ suggesting that the normal net electronegative charge of the glomerular capillary wall was not altered. Fractional clearances of macromolecular neutral dextrans were similar in diabetic and normal rats throughout a wide range of molecular size $(18-42 \AA)$. Glomerular filtration rate was the same in the two groups of rats $(2.77 \pm 0.16 \mathrm{ml} / \mathrm{min}$ in diabetics and $2.72 \pm 0.11 \mathrm{ml} /$ min in normals) suggesting that renal haemodynamic factors did not influence fractional clearances of neutral dextrans in diabetic rats. We conclude that the proteinuria exhibited by these chronically diabetic rats is not attributable to alterations of size-selective properties of the glomerular capillary wall, such as increases in the size or the number of pores.

Key words: Streptozotocin diabetes, proteinuria, glomerular permeability, glomerular filtration rate, fractional clearances of neutral dextrans, glomerular pores

Proteinuria is the predominant abnormality of renal function in rats with experimental diabetes mellitus [1-4]. The pathogenesis of proteinuria in this experimental model of diabetic nephropathy has not been elucidated. The glomerulus normally functions as an effective barrier to filtration of serum proteins based on their size, net electrical charge [5], and steric configuration [6]. Structural alterations of the glomerular capillary in diabetes have been postulated to enhance porosity of the glomerulus, thereby diminishing its effectiveness as a selective filter $[7,8]$. In this study, we have examined the fractional clearances of a polydisperse population of neutral dextrans for the purpose of determining whether alterations in the size-selective properties of the glomerular capillary wall contribute to the proteinuria of chronic experimental diabetes.

\section{Materials and Methods}

Two groups of female Munich-Wistar rats were studied [1] 5 rats with streptozotocin-induced $(50 \mathrm{mg} / \mathrm{kg}$ ) diabetes mellitus (DM) of 7-10 months duration, and [2] 5 age-matched normal control (NC) rats. Free access was provided to standard laboratory chow and tap water. Prior to study, all rats were placed in individual metabolic cages for monitoring of 24-hour excretion rates of urinary volume, glucose, and protein.

Rats were surgically prepared for clearance studies under light ether anaesthesia. Cannulae were placed in a jugular vein for infusions and in a femoral artery for sampling of blood and measurement of blood pressure. A soft silastic catheter was passed transurethrally into the bladder, and a snugly tied suture was placed circumferentially around the external urethra in order to prevent leakage of urine around the catheter. Rats were then placed in a plastic restraining cage and permitted to awaken and stabilise for $2-3 \mathrm{~h}$. During that time, a priming dose $(8 \mu \mathrm{Ci})$ of ${ }^{14} \mathrm{C}$-inulin (New England Nuclear, Boston, Mass.) was administered and followed by an infusion at $0.02 \mathrm{ml} / \mathrm{min}$ of $0.154 \mathrm{~mol} / \mathrm{l}$ saline containing $4 \mu \mathrm{Ci} / \mathrm{ml}{ }^{14} \mathrm{C}$-inulin. Additional volumes of $0.154 \mathrm{~mol} / 1$ saline were infused as needed to maintain the rate of fluid delivery equal to the rate of urine flow.

After urine flow had stabilised, two consecutive 15 minute clearance studies were performed, with blood being sampled at the midpoint of each. During a third 15 minute period, fractional clearances of neutral dextrans were determined in the following manner. Tritiated dextrans of a wide molecular size distribution, prepared according to the method of Chang et al. [9], were 
Table 1. Comparison of metabolic and renal function data in normal and chronically diabetic rats

\begin{tabular}{lccc}
\hline & $\begin{array}{c}\text { Diabetic } \\
(\mathrm{n}=5)\end{array}$ & $\begin{array}{c}\text { Control } \\
(\mathrm{n}=5)\end{array}$ & $\mathrm{p}$ \\
\hline Body weight $(\mathrm{g})$ & $174 \pm 10$ & $214 \pm 2$ & $<0.005$ \\
Plasma glucose $(\mathrm{mg} / \mathrm{dl})$ & $440 \pm 81$ & $132 \pm 10$ & $<0.001$ \\
Urine volume $(\mathrm{ml} / 24 \mathrm{~h})$ & $103 \pm 11$ & $20 \pm 1$ & $<0.001$ \\
Urine glucose $(\mathrm{g} / 24 \mathrm{~h})$ & $9.2 \pm 1.4$ & 0 & $<0.001$ \\
GFR $(\mathrm{ml} / \mathrm{min})$ & $2.77 \pm 0.16$ & $2.72 \pm 0.11$ & $\mathrm{NS}$ \\
GFR/100 $\mathrm{g}$ body weight & & & \\
$\quad(\mathrm{ml} / \mathrm{min})$ & $1.59 \pm 0.02$ & $1.27 \pm 0.04$ & $<0.001$ \\
Urine protein $(\mathrm{mg} / 24 \mathrm{~h})$ & $39 \pm 7$ & $4.7 \pm 0.2$ & $<0.005$ \\
Urine albumin $(\mathrm{mg} / 24 \mathrm{~h})$ & $2.0 \pm 0.6$ & $1.6 \pm 0.3$ & $\mathrm{NS}$ \\
Urine albumin/protein $(\%)$ & $5.5 \pm 1.0$ & $33.3 \pm 5.0$ & $<0.001$ \\
Urine albumin & & & \\
$\quad(\mathrm{mg} / 24 \mathrm{~h} / 100 \mathrm{~g}$ body & $1.24 \pm 0.31$ & $0.74 \pm 0.11$ & $\mathrm{NS}$ \\
$\quad$ weight $)$ & & & \\
\hline
\end{tabular}

Values are mean \pm SEM

NS, not statistically significant $(p>0.05) ; n=$ number of rats

a significance of the difference between normal and diabetic rats

administered IV as a bolus injection $(5 \mu \mathrm{Ci}$ in $0.5 \mathrm{ml})$ followed immediately by infusion of the same solution at $0.045 \mathrm{ml} / \mathrm{min}$. About $90 \mathrm{~s}$ after completing injection of the priming dose, continuous collection of blood from the femoral artery was begun by means of a withdrawal pump (Model 944, Harvard Apparatus Co., Willis, Mass.) at a constant rate equal to the infusion rate of ${ }^{3}-\mathrm{H}-$ dextran. Collection of urine was begun about $90 \mathrm{~s}$ after beginning the continuous withdrawal of femoral arterial blood and finished at the same time interval after stopping the 15-minute collection of blood. The time intervals between administration of the priming dose and initiation of blood collection and between collections of blood and urine were identical in individual rats and were equal to the "transit time" for an IV bolus $(0.05 \mathrm{ml})$ of $3 \%$ Lissamine Green to appear in the urine. This clearance method is recommended by Chang et al. [9] for the purpose of enhancing accuracy of dextran clearance measurements. The percent deviation from the mean for the 3 GFR determinations in individual rats was $6.9 \pm 0.5 \%$ (SEM), and the mean coefficient of variation for the 10 rats was $9.4 \%$.

\section{Analytical Methods}

The $24 \mathrm{~h}$ urine samples and plasma samples collected prior to the clearance studies were analysed for glucose using a Beckman Glucose Analyzer (Beckman Instruments, Inc., Fullerton, Ca.). Urinary total protein was measured by the Coommassie blue proteindye binding assay of Bradford (10) (Bio-Rad Laboratories, Richmond, California). The urinary excretion of albumin per $24 \mathrm{~h}$ was assayed by electrophoresis on a $10 \%$ polyacrylamide slab gels by the method of Kahn and Rubin [11]. After staining the gel with Coommassie brilliant blue, each specific albumin band was scanned (Gilford Instrument Laboratories, Inc., Oberlin, Ohio), and the area under each uniform peak was measured with an electronic graphics calculator (Numonics Corpaoration, Lansdale, Pennsylvania). The quantity of urinary albumin was derived from a standard curve of peak areas for five different quantities (from 50-1000 ng) of bovine serum albumin electrophoresed concurrently with the urine samples. Analysis of 17 consecutive protein solutions detected $103.9 \pm 2.2 \%$ (SEM) of the albumin present.

Samples of urine and plasma from the three clearance periods were analysed for ${ }^{14} \mathrm{C}$-inulin by liquid scintillation (Packard Tri-
Carb Spectrophotometer Model 3390, Packard Instruments, Inc., Downers Grove, Illinois).

The chromatographic methods of Chang et al. [9] were employed for separating dextrans of varying molecular size. The G-100 Sephadex columns were calibrated using dextran $T_{10}, T_{20}$, $T_{40}, T_{80}$ and as many as seven different biological proteins with molecular weights ranging from 12,500 to 150,000 . The fractional volume available to test dextrans and test proteins $\left(\mathrm{k}_{\mathrm{av}}\right)$ was plotted against the log of the respective Stokes-Einstein radii yielding a linear relationship identical to that reported by others [9]. Samples of $100 \mu \mathrm{l}$ of plasma and urine obtained during the third clearance period were mixed with $200 \mu \mathrm{l}$ of $0.01 \mathrm{~mol} / 1$ ammonium acetate buffer $(\mathrm{pH} 7.0)$ and $1.0 \mathrm{mg}$ of blue dextran and chromatographed on a calibrated $95 \times 1.5 \mathrm{~cm}$ column of Sephadex G-100. Each $2 \mathrm{ml}$ fraction collected in a position corresponding to the elution of molecules with a size from 18 to 42 angstroms $(\AA)$ were individually added to $7 \mathrm{ml}$ Aquasol (New England Nuclear, Boston, Mass.) in a counting vial and thoroughly mixed so that a gel formed. The ${ }^{3} \mathrm{H}$-dextran and ${ }^{14} \mathrm{C}$-inulin in each fraction were counted, making appropriate corrections for quenching and crossover.

\section{Calculations}

GFR was calculated as the urine-to plasma (U/P) concentration ratio of inulin times the urinary flow rate. The fractional clearances of dextrans were calculated as the U/P ratio for each molecular size dextran divided by the U/P ratio of inulin. Statistical analyses were performed using the Student $t$ test [12]. Data are expressed as the mean $\pm S E M$.

\section{Results}

Metabolic and renal function data for diabetic and age-matched control rats are shown in Table 1 . The diabetic rats weighed less than the normal rats ( 174 vs $214 \mathrm{~g}, \mathrm{p}<0.005$ ). Intermittent assays of nonfasting blood glucose indicated that comparable levels of hyperglycaemia persisted throughout the course of diabetes in each rat ( $460 \pm 79$ at one month of diabetes and $440 \pm 81$ at $7-10$ months). At the time of the studies, the rats also were found to be intensely glycosuric $(9.2 \pm 1.4 \mathrm{~g} / 24 \mathrm{~h})$ and polyuric $(103 \pm 11 \mathrm{ml} /$ $24 \mathrm{~h})$.

Proteinuria in diabetic rats was greater than in normal rats ( 39 vs $5 \mathrm{mg} / 24 \mathrm{~h}, \mathrm{p}<0.005$ ). Urinary excretion of albumin was similar in the two groups $(2.0 \pm 0.6 \mathrm{mg} / 24 \mathrm{~h}$ in diabetics and $1.6 \pm 0.3 \mathrm{mg} / 24 \mathrm{~h}$ in normals). If corrected for differences in body weight, diabetic rats exhibited slightly higher albumin excretion $(1.24 \pm 0.31$ versus $0.74 \pm 0.11 \mathrm{mg} / 24 \mathrm{~h} /$ $100 \mathrm{~g}$ body weight), but the difference between the groups failed to attain statistical significance. The contribution of albumin to the total urinary protein was much less in the diabetic group $(5.5 \%$ versus $33.3 \%, \mathrm{p}<0.001)$.

The mean values for absolute GFR were virtually identical for each group of rats $(2.77 \pm 0.16 \mathrm{ml} / \mathrm{min}$ in diabetics vs $2.72 \pm 0.11 \mathrm{ml} / \mathrm{min}$ in normals); however, 
Table 2. Fractional clearances ${ }^{\mathrm{a}}$ of neutral dextrans of varying effective molecular radii in normal and chronically diabetic rats

\begin{tabular}{lrrrrrrrrrrrrr}
\hline & $18 \AA$ & \multicolumn{1}{c}{$20 \AA$} & \multicolumn{1}{c}{$22 \AA$} & \multicolumn{1}{c}{$24 \AA$} & $26 \AA$ & $28 \AA$ & $30 \AA$ & $32 \AA$ & $34 \AA$ & $36 \AA$ & $38 \AA$ & $40 \AA$ & $42 \AA$ \\
\hline Normal & 1.01 & 0.99 & 0.96 & 0.91 & 0.83 & 0.71 & 0.59 & 0.46 & 0.34 & 0.22 & 0.14 & 0.07 & 0.03 \\
$(\mathrm{n}=5)$ & \pm 0.03 & \pm 0.03 & \pm 0.03 & \pm 0.02 & \pm 0.02 & \pm 0.03 & \pm 0.02 & \pm 0.02 & \pm 0.02 & \pm 0.01 & \pm 0.01 & \pm 0.01 & \pm 0.01 \\
Diabetic & 0.94 & 0.93 & 0.90 & 0.82 & 0.75 & 0.64 & 0.52 & 0.40 & 0.29 & 0.20 & 0.12 & 0.07 & 0.04 \\
$(\mathrm{n}=5)$ & \pm 0.08 & \pm 0.08 & \pm 0.08 & \pm 0.06 & \pm 0.07 & \pm 0.06 & \pm 0.04 & \pm 0.03 & \pm 0.03 & \pm 0.02 & \pm 0.01 & \pm 0.01 & \pm 0.01 \\
$\mathrm{p}$ & $\mathrm{NS}$ & $\mathrm{NS}$ & $\mathrm{NS}$ & $\mathrm{NS}$ & $\mathrm{NS}$ & $\mathrm{NS}$ & $\mathrm{NS}$ & $\mathrm{NS}$ & $\mathrm{NS}$ & $\mathrm{NS}$ & $\mathrm{NS}$ & $\mathrm{NS}$ & $\mathrm{NS}$ \\
\hline
\end{tabular}

Data are mean \pm SEM

NS, not significant $(\mathrm{p}>0.05) ; \mathrm{n}=$ number of rats

${ }^{a}$ Fractional clearance refers to the ratio of the renal clearance of neutral dextran to the simultaneously determined clearance of inulin

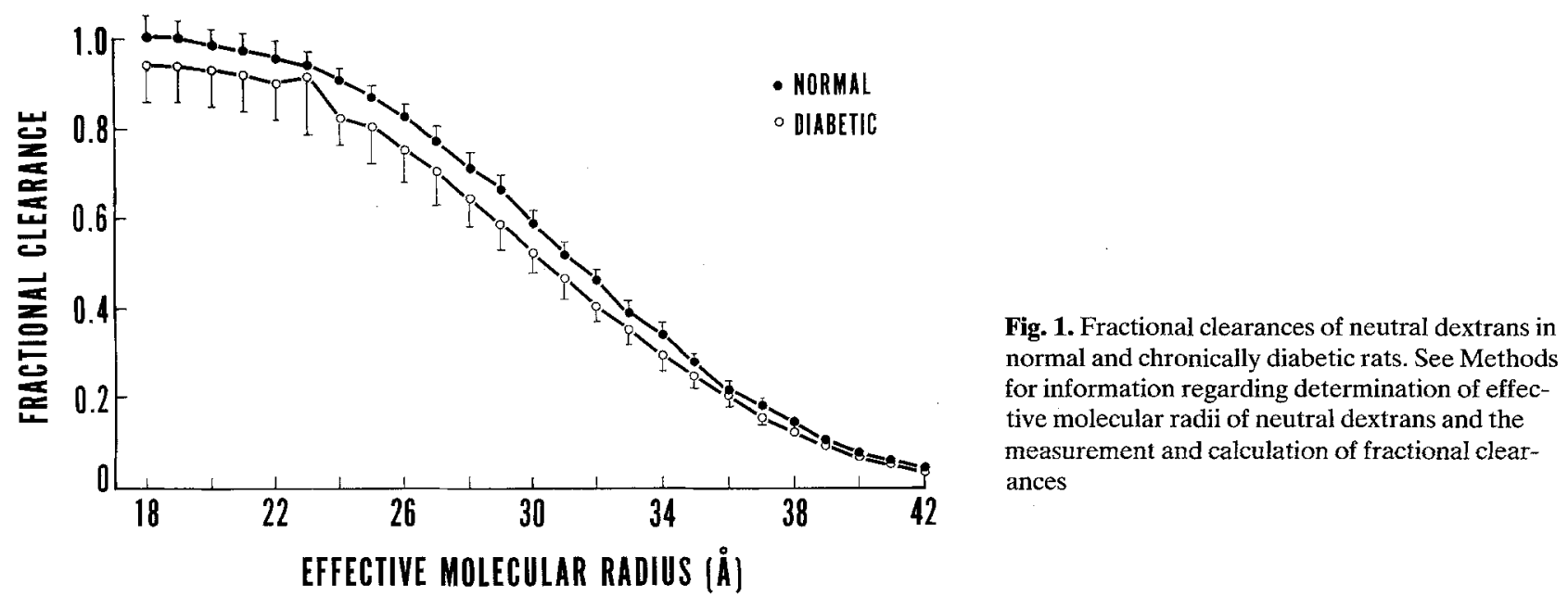

if corrected for body weight, the mean value for GFR was slightly but significantly greater in diabetic rats (Table 1).

Data for the fractional clearances of neutral dextrans in both normal and diabetic rats are illustrated in Figure 1 and Table 2. In normal hydropenic rats, restriction of dextran filtration was not measurable until the effective molecular radius exceeded $22 \AA$. The fractional clearances of neutral dextrans progressively decreased as molecular size increased. The fractional clearances of macromolecular neutral dextrans were not different in normal hydropenic rats and chronically diabetic rats with proteinuria.

\section{Discussion}

Rats given streptozotocin develop the metabolic aberrations characteristic of human diabetes mellitus and a glomerulopathy histologically manifested by increased mesangium $[1,2,4,13,14]$ and thickening of the glomerular basement membrane [14], and functionally manifested by proteinuria $[1,2,4,16]$. We recently reported that rats with severe, long-term experimental diabetes have normal glomerular filtra- tion rates and renal plasma flow [4]. In the present study, the mean value of GFR in rats chronically diabetic for 7-10 months again was found to be the same as in age-matched normal rats, although slightly higher if factored by body weight. However, correcting renal clearance data for body weight in diabetic rats is of dubious validity since GFR and body weight are likely to be independent variables separately affected by metabolic aberrations of the diabetic process. Further obscuring any possible relationship between body weight and GFR is the observation that diabetic rats may have larger kidneys and larger glomeruli than normal rats [17]. Nevertheless, this experimental model of diabetic nephropathy is characterised functionally by proteinuria unaccompanied by renal insufficiency.

Although proteinuria has emerged as the primary functional abnormality of the kidneys in diabetic rats [1-4], the responsible pathogenic mechanisms have not been elucidated. The present study was undertaken to evaluate whether the proteinuria observed in chronically diabetic rats resulted from alteration in the size-selective properties of the glomerular capillary wall. Macromolecules of the size of inulin $(\sim 14 \AA)$, or smaller, readily traverse the 
glomerulus so that they appear in the fluid within Bowman's space in the same concentration as in plasma water [9]. Dextran, like inulin, is filtered and neither reabsorbed nor secreted by the tubules so that the urinary excretion of macromolecular dextrans of varying molecular size is a function of filtration by the glomerulus [9]. As the effective molecular radius of the dextrans increases, passage through the glomerulus becomes progressively restricted [9]. Accordingly, the ratio of the clearance of neutral dextran of a given molecular size to the clearance of inulin provides an index of the size selective properties of the glomerular capillary wall. In normal animals, the ratio is 1.0 for neutral dextrans of low molecular size ( $\leqq 20 \AA)$ and it progressively falls towards zero for larger dextran molecules $(\leqq 42 \AA)$ (Fig. 1 and Table 2).

In experimental diabetic glomerulopathy, an increase in either the number or size of glomerular pores could result in an impaired ability to restrict filtration of serum proteins. Finding an increase in the fractional clearances of macromolecular neutral dextrans would provide support for this hypothetical mechanism of proteinuria in diabetes. However, in this study the fractional clearances of neutral dextrans were similar in diabetic and age-matched normal rats. Thus, proteinuria in our chronically diabetic rats cannot be attributed to an increase in number or size of glomerular pores.

Mogensen found normal fractional clearances of neutral dextrans in human subjects with early diabetes, although they were not clinically proteinuric [18]. On the other hand, Carrie and Myers recently reported that diabetic patients with heavy proteinuria $(>2 \mathrm{~g} / \mathrm{d})$ and albuminuria exhibited depressed fractional clearances of neutral dextrans with effective molecular radii of $24-36 \AA$ while fractional clearances of smaller and larger molecules were normal [19]. These results are compatible with a reduction in size or number of glomerular pores in patients with diabetic nephropathy and heavy proteinuria.

Since the fractional clearances of macromolecules may be influenced not only by the selective permeability properties of the glomerular capillary wall per se but also by haemodynamic factors that determine glomerular filtration, an alternative interpretation of our results is possible. In confirmation of their theoretical analysis [20], Chang and colleagues have shown that the fractional clearances of intermediatesized $(25-35 \AA)$ neutral dextrans are diminished when glomerular plasma flow, and filtration rate, are increased [9]. Hence, it is conceivable that an upward displacement of the fractional clearances of neutral dextrans owing to increased number and/or size of glomerular pores could have been obscured by off- setting influences of hyperfiltration in the diabetic group. This possibility seems unlikely as GFR was the same in both groups of rats.

The glomerular capillary wall normally possesses a net negative electrical charge owing to the presence on the epithelial surface of glycoproteins containing sialic acid [21, 22]. These glomerular polyanions appear to retard filtration of negatively charged macromolecules (such as albumin) to a greater extent than uncharged macromolecules of equivalent size [23]. In both clinical and experimental renal diseases manifested by heavy proteinuria, fractional clearances of uncharged macromolecules have been decreased while excretion of negatively charged macromolecules were increased, suggesting diminished charge-selectivity of the glomerular barrier, possibly resulting from reduced glomerular polyanion [24-27]. If the loss of negative glomerular charges that has been found in people with advanced diabetic nephropathy $[28,29]$ were also to occur in diabetic rats, then one might expect them to demonstrate a substantial increase in the excretion of negativelycharged proteins, such as albumin. Increases in albumin excretion of small magnitude have been observed previously in chronically diabetic rats $[16$, 30]. Albumin, however, has not been shown to be the dominant urinary protein in chronically diabetic rats [3]. We found no difference in absolute rates of albumin excretion in diabetic and normal rats. Factoring by body weight suggests greater albuminuria in diabetic than normal rats, but the difference fails to attain statistical significance and is of doubtful biological significance, particularly as albumin comprised only about $6 \%$ of the total protein in diabetic urine. Hence, to the extent that albuminuria per se may serve as an index of enhanced filtration of negatively charged macromolecules, it seems unlikely that a substantial impairment of charge-selectivity of the glomerulus underlies the proteinuria observed in our diabetic rats.

Acknowledgements. The authors are grateful for the secretarial assistance of Mrs. Rosa Mari Alvarez and Ms. Alicia Rivas.

We are particularly appreciative of the assistance of Dr. T. J. Mende of the Department of Biochemistry in the preparation of the tritiated dextran.

This work was supported by National Institutes of Health Grants 1 RO1 AM20735, 7 RO1 AM19822, and 1 T32 AMO7205. Dr. Bourgoignie is an Investigator of the Howard Hughes Medical Institute.

\section{References}

1. Weil R, Nozawa M, Koss M, Weber C, Reemtsma K, McIntosh $R$ (1975) Pancreatic transplantation in diabetic rats: Renal function, morphology, ultrastructure and immunohistology. Surgery 78 : 142-148 
2. Weil R, Nozawa M, Koss M, Weber C, Reemtsma K, McIntosh R (1976) The kidney in streptozotocin diabetic rats. Arch Pathol Lab Med 100: 37-49

3. Weber CJ, Silva FG, Hardy MA, Pirani CL, Reemtsma K, (1979) Effects of islet transplantation on renal function and morphology of short-and long-term diabetic rats. Transplant Proc 11: 549-556

4. Selawry HP, Pennell JP, Pardo V, Alzamora DB, Millard MM (1980) The effects of culture-maintained pancreatic islets on metabolic parameters, renal function, and glomerular lesions in the diabetic rat. Metabolism 29: 261-269

5. Brenner BM, Hostetter TH, Humes HD (1978) Glomerular permselectivity: Barrier function based on discrimination of molecular size and charge. Am J Physiol 234: F455-F459

6. Bohrer MP, Deen WM, Robertson CR, Troy JP, Brenner BM (1978) Influence of molecular configuration on the glomerular filtration of macromolecules. Kidney Int 14: 751

7. Trap-Jensen J (1971) Permeability of small blood vessels in diabetes. In: Lundbaek K, Keen $\mathrm{H}$ (eds) Blood vessel disease in diabetes mellitus, V Capri Conference. The Publishing House "il Ponte", Milan, p 192-202

8. Spiro RG (1976) Search for a biochemical basis of diabetic microangiopathy. Diabetologia 12: 1-14

9. Chang RLS, Ueki IF, Troy JL, Deen WM, Robertson CR, Brenner BM (1975) Permselectivity of the glomerular capillary wall to macromolecules II. Experimental studies in rats using neutral dextran. Biophys J 15: 887-906

10. Bradford M (1976) A rapid and sensitive method for quantitation of microgram quantities of protein utilizing the principle of protein-dye binding. Anal Biochem 72: 248-254

11. Kahn R, Rubin RW (1975) Quantitation of submicrogram amounts of protein using Coomassie Brillant Blue on sodium dodecyl sulfate-polyacrylamide slab-gels. Anal Biochem 67: 347-352

12. Snedecor GW (1956) Statistical methods, 5th ed. Iowa State University Press, Ames, Iowa

13. Mauer SM, Sutherland DER, Steffles MW, Leonard RJ, Najarian JS, Michael AF, Brown DM (1974) Pancreatic islet transplantation. Effects on the glomerular lesions of experimental diabetes in the rat. Diabetes 23: 748-753

14. Rasch R (1979) Prevention of diabetic glomerulopathy in streptozotocin diabetic rats by insulin treatment: The mesangial regions. Diabetologia 17: 243-248

15. Rasch R (1979) Prevention of diabetic glomerulopathy in streptozotocin diabetic rats by insulin treatment. Glomerular basement membrane thickness. Diabetologia 16: 319-324

16. Mauer SM, Brown DM, Matos AJ, Steffles MW (1978) Effects of pancreatic islet transplantation on the increased urinary albumin excretion rates in intact and uninephrectomized rats with diabetes mellitus. Diabetes 27: 954-964

17. Rasch R (1979) Prevention of diabetic glomerulopathy in streptozotocin diabetic rats by insulin treatment. Kidney size and glomerular volume. Diabetologia 16: 125-128

18. Mogensen CE (1971) Kidney function and glomerular per- meability to macromolecules in early juvenile diabetes. Scand J Clin Invest 28: 79-90

19. Carrie BJ, Myers BD (1980) Proteinuria and functional characteristics of the glomerular barrier in diabetic nephropathy. Kidney Int 17: 669-676

20. Chang RLS, Robertson CR, Deen WM, Brenner BM (1975) Permselectivity of the glomerular capillary wall to macromolecules I. Theoretical considerations. Biophys J 15: 861886

21. Jones DB (1969) Mucosubstances of the glomerulus. Lab Invest 21: 119-125

22. Micheal AF, Blau E, Vernier RL (1970) Glomerular polyanion: Alteration in aminonucleoside nephrosis. Lab Invest 23: 649-657

23. Chang RLS, Deen WM, Robertson CR, Brenner BM (1975) Permselectivity of the glomerular capillary wall: III. Restricted transport of polyanions. Kidney Int 8: 212-218

24. Robson AM, Giangiacomo J, Keinstra RA, Naqvi ST, Inglefinger JR (1974) Normal glomerular permeability and its modification by minimal change nephrotic syndrome. J Clin Invest 54: 1190-1199

25. Chang RLS, Deen WM, Robertson CR, Bennett CM, Glassock RJ, Brenner BM (1976) Permselectivity of the glomerular capillary wall. Studies of experimental glomerulonephritis in the rat using neutral dextran. J Clin Invest 57: 1272-1286

26. Deen WM, Robertson CR, Brenner BM (1976) Permselectivity of the glomerular capillary wall. Studies of experimental glomerulonephritis in the rat using dextran sulfate. $\mathbf{J}$ Clin Invest 57: 1287-1294

27. Bohrer MP, Baylis C, Robertson CR, Brenner BM (1977) Mechanism of the puromycin-induced defects in the transglomerular passage of water and macromolecules. J Clin Invest 60: 152-161

28. Westberg NG, Michael AF (1973) Human glomerular basement membrane chemical composition in diabetes mellitus. Acta Med Scand 194: 39-47

29. De Bats A, Gordon AH, Rhodes EL (1974) Variation in glomerular sialic acid content in diabetes and as the result of ageing. Clin Sci Mol Med 47: 93-95

30. Rasch R (1980) Prevention of diabetic glomerulopathy in streptozotocin diabetic rats by insulin treatment. Albumin excretion. Diabetologia 18: 413-416

Received: March 5, 1980,

and in revised form: October 13, 1980

J. Phillip Pennell, M. D.

Division of Nephrology

Department of Medicine (R-126)

University of Miami School of Medicine

P. O. Box 016960

Miami, FL 33101

USA 